Brit. J. industr. Med., 1965, 22, 187.

\title{
VENTILATORY CAPACITY ON EXPOSURE TO JUTE DUST AND THE RELEVANCE OF PRODUCTIVE COUGH AND SMOKING TO THE RESPONSE
}

\author{
BY \\ BRYAN GANDEVIA and JAMES MILNE \\ From the Division of Thoracic Medicine, Department of Medicine, Prince Henry Hospital, \\ and University of New South Wales, Sydney, and the Division of Industrial Hygiene, \\ Victorian Health Department, Melbourne, Australia
}

(RECEIVED FOR PUBLICATION NOVEMBER 3, 1964)

\begin{abstract}
The ventilatory capacity of 46 men exposed to jute dust in the manufacture of felt and wadding was estimated at the beginning and end of shifts on the first and last days of a working week. A smoking history was obtained from all subjects, and for those speaking English a more detailed questionnaire on respiratory symptoms was completed. Each man was also instructed to cough under observation, and a loose cough, as judged by ear or by production of a sputum specimen was recorded as productive. A significant mean decrease in forced expiratory volume at one second was observed in the series as a whole on the first day at work, but no significant change was found over the final day nor over the entire week. Closer analysis reveals that this decrease was largely confined to those with a productive cough on request, and to those who smoked, most of the former group being smokers. In these groups the decrease observed on the first day tended to persist throughout the week. Insofar as those who smoked, and particularly those who had a productive cough, tended to have a lower F.E.V.1.0 vital capacity, the men with the greater initial impairment of ventilatory capacity showed the more significant decreases on exposure to dust. Evidence is produced to suggest that the sign of productive cough defines better than the history a group with a lower ventilatory capacity and a greater tendency to react to inhaled irritants.
\end{abstract}

Concurrently with a study of ventilatory capacity changes in cotton workers it was decided to investigate in a comparable way workers exposed to another dust in a factory in the same industrial area of Sydney. The selected factory manufactured felt and wadding, chiefly from woven Pakistan jute and from old, used hessian sacks, with rags, raw cotton, and animal hair as minor constituents. This paper records the results of tests of ventilatory capacity performed at the beginning and end of two shifts early and late in the working week. The data are related in particular to the smoking habits of the subjects and to the presence or absence of sputum when they were asked to cough under observation, but the possible relevance of initial ventilatory capacity, duration of employment, and a history of chronic bronchitis is also examined.

\section{The Factory and Relevant Processes}

The felting department, where most of the employees studied were working, occupies about two-thirds of an area approximately $120 \mathrm{ft} . \times 100 \mathrm{ft}$. The raw materials which do not include cotton, are teased in a picker; the lighter fragments are sucked upwards into feed bins while larger particles fall and go through the picking process again. From the feed bins the picked material is hand-fed to a hopper from which a spiked apron carries appropriate quantities past spiked rollers. This garnetting machine cards the composite material, in a manner similar to wool and cotton carding machines, to form a web which is then lapped several times and the resulting wad pressed and rolled. In a needling machine the wads are interleaved with hessian sheets and machine- 
sewn to interlock the fibres. These processes are all in some degree dusty, the garnetting process particularly so; the entire factory area is hazy during the working day. A new machine incorporating all these processes is also in operation in the area, and, being partly enclosed and exhausted, it produces less dust than the older, individual machines.

The wadding process, occupying most of the remainder of the factory area, is similar but is generally much less dusty, contributing very little if anything to the haze surrounding the main jute processing area. Raw or low-grade cotton from India, cotton waste, rags (which, by New South Wales law, must be new), and flock are blended in a picker and conveyed to two garnets. The product is then lapped, rolled, and cut to desired sizes.

Jobs that are intermittently dusty are also to be found in the bale-breaking and dust collection areas. Other processes which might conceivably affect ventilatory capacity are concerned with finishing, and involve the use of size, glue or latex. These processes are intermittent or occasional and involve only a small proportion of the work force which in any case is exposed to the dust of the general factory area. In the circumstances obtaining at the time of the study, these processes were considered unlikely to influence the overall picture.

One intermittent task requires mention since five men were engaged on it for the whole of the second shift to be studied. It involves the breaking of bales of goat hair, much of which is uncleansed, and its teasing, a process which probably liberates the tanner's lime as a fine dust together with some fragmented hair. This was regarded by the management and employees as an unpleasant job, causing cough and irritation of the eyes, and the men periodically assigned to it wore ineffective gauze masks to minimize cough.

Adjacent areas of the factory, such as the fitter's assembly shop and store, provided a group of workers with minimal, but not necessarily negligible, dust exposure, depending largely on the time which they might be required to spend in the main factory area.

Consideration of the nature of the various processes, the relative quantities of raw materials, and the geography of the factory leaves no doubt that jute was the major dust to which the men as a group were exposed in greater or lesser degree. The overall magnitude of the dust problem may be gauged from the fact that, in processing, about $30 \%$ by weight of the raw materials is lost as dust. An appropriate instrument for quantitatively assessing the dust was not available at the time of the study. By eye, the working conditions in the main factory area on Tuesday and Friday would both be classified as exceedingly dusty, and there is no reason, having regard to the work being done, to consider that the dust concentrations varied on these two days. If anything, the long weekend break might have meant less dusty conditions in the early part of Tuesday.

\section{Plan of the Investigation}

All the men employed in the main factory area and in the bale-breaking room were studied, together with all the fitters and storemen available at the time of the first test. All were interviewed by one of us (B.G.) at some time during the survey, and for the 25 men speaking sufficient English the British Medical Research Council's short questionnaire on respiratory symptoms (1960), with some additional questions, was completed. From those not fluent in English, only a smoking history and the results of mass radiography examination were obtained. All the employees had had a normal chest radiograph in the preceding 18 months, none claimed to have an abnormal exercise tolerance, and none of those adequately interrogated gave a history suggestive of byssinosis. Smoking habit ranged from one to 30 cigarettes daily; three men smoked less than 10 cigarettes a day, and seven men smoked over 25 per day.

At the beginning of two shifts, before the histories had been taken and before the ventilatory tests had been done, each man was instructed to take a deep breath and to cough whilst under observation in an attempt to expectorate a sputum specimen into a container. A loose cough, as judged by ear, was recorded as productive even if no specimen was in fact produced. Ten subjects were recorded as having a productive cough on the first occasion and six, including three previously recognized, on the second occasion; for purposes of analysis, the sign has therefore been regarded as positive in 13 subjects.

The forced expiratory volume at one second (F.E.V.1.0) and forced vital capacity (F.V.C.) were read (J.M.) directly from the scale of a Godart pulmometer with the subject seated. The highest of three 'consistent' estimates (within $5 \%$ for F.E.V.1.0) was used in the analysis. About half the employees, watched by the remainder, were given a 'practice blow' on the day before the investigation proper commenced. Subsequent analysis showed no numerical evidence of different performance by those who had this trial and those who had not, but the familiarity of the entire series with the idea of the test speeded up the process. All employees were studied at the beginning and end of the Tuesday shift (Monday was a public holiday) and similarly on the following Friday. The symbols A, B, C, and D are respectively allotted to the values for Tuesday morn- 
ing, Tuesday afternoon, Friday morning, and Friday afternoon.

The work processes and each man's job were reviewed, and the latter were classified as affording minimal, moderate or severe dust exposure. Any possible exposures to cotton dust or latex spray on the test days were noted, but, since the 12 men who might have had transient or slight exposure to one or both of these (in addition to jute) showed changes in ventilatory capacity no different from those of the entire series, no further consideration is given to these possible hazards. On the Friday, five men worked for the entire shift on the goat hair bales. On this day, their average decrease in F.E.V..$_{\cdot 1 \cdot 0}$ over the shift was $206 \mathrm{ml}$. (P $<0.10>0.05)$, compared with $72 \mathrm{ml}$. ( $\mathrm{P}<0.60>0.50)$ on the Tuesday when exposed to jute alone. This finding may suggest a real hazard, in terms of ventilatory capacity response, for it was consistent for each of the five men, and was rather the reverse of the findings for Tuesday and Friday for the entire series, in which the greater average decrease was observed on Tuesday. However, the difference in ventilatory response on Tuesday and on Friday in those exposed to goat hair on Friday failed to reach statistical significance $(P<$ $0.40>0.30$ ), and so for simplicity of presentation these results have not been excluded from the analysis given below. In fact their inclusion does not modify any of the statistical conclusions nor does it influence any of the arguments to be developed.

Of the 46 men tested on the Tuesday, six were not available on the Friday; four were absent (Thursday is pay day), one recent employee had resigned (the work was 'too dusty'), and one, who had shown a slight rise in F.E.V $\cdot_{\cdot 1 \cdot 0}$ during Tuesday, refused further tests. The mean change in F.E.V.1.0 these six men was of the same order as that for the entire series, and again, where possible, we have included their results in the statistical analysis.

Weather conditions remained pleasingly stable (fine and mild with relatively cold mornings) throughout the study and there were no major fluctuations in air pollution levels. The temperature in the factory ranged from $16^{\circ} \mathrm{C}$. to $21^{\circ} \mathrm{C}$., with $1.5^{\circ}$ and $2.5^{\circ}$ rises during the two shifts. No temperature correction was applied to the ventilatory measurements.

\section{Results}

General Review.-A summary of the mean values for F.E.V $\cdot{ }_{1 \cdot 0}$ and F.V.C. is shown in Table 1. A small decrease in the average F.E.V.1.0 days without notable changes in F.V.C., and the subsequent analysis is therefore based primarily on the changes observed in the F.E.V.1.0 during each working day and over the entire week. Tables 2 to 8 set out the results of statistical analyses based on the changes in F.E.V.1.0, and, where appropriate, the results of comparisons between these differences. In the text, reference to the relevant statistical data is made by means of the number in the left-hand column of the appropriate table, and the term 'significant' implies $\mathbf{P}<0.05$.

During Tuesday, the first day at work after a long weekend, a significant mean decrease in F.E.V.1.0 of $85 \mathrm{ml}$. (Table 2.1) was observed. Statistically insignificant decreases of the order of $60 \mathrm{ml}$. were noted on Friday (Table 2.2) and over the entire week

TABLE 1

MEAN VALUES FOR F.E.V.1.0 AND F.V.C. (LITRES, A.T.P.S.)

\begin{tabular}{|c|c|c|c|c|c|c|c|c|}
\hline & \multicolumn{2}{|c|}{$A^{*}$} & \multicolumn{2}{|c|}{$\mathrm{B}^{*}$} & \multicolumn{2}{|c|}{$C^{*}$} & \multicolumn{2}{|c|}{$\mathbf{D}^{*}$} \\
\hline & F.E.V. ${ }_{-1 \cdot 0}$ & F.V.C. & F.E.V.1.0 & F.V.C. & F.E.V.1•• & F.V.C. & F.E.V.1.0 & F.V.C. \\
\hline $\begin{array}{l}\text { Entire series } \\
\mathrm{n}=46\end{array}$ & $\begin{array}{c}3 \cdot 11 \\
(0 \cdot 62)\end{array}$ & $\begin{array}{c}3.84 \\
(0.59)\end{array}$ & $\begin{array}{c}3.02 \\
(0.68)\end{array}$ & $\begin{array}{c}3.81 \\
(0.62)\end{array}$ & & & & \\
\hline $\begin{array}{l}\text { Series less defaulters } \\
n=40\end{array}$ & $\begin{array}{c}3.08 \\
(0.76)\end{array}$ & $\begin{array}{c}3.85 \\
(0.61)\end{array}$ & $\begin{array}{c}3.01 \\
(0.72)\end{array}$ & $\begin{array}{c}3.82 \\
(0.65)\end{array}$ & $\begin{array}{c}3 \cdot 10 \\
(0 \cdot 73)\end{array}$ & $\begin{array}{c}3.91 \\
(0.65)\end{array}$ & $\begin{array}{c}3.05 \\
(0.70)\end{array}$ & $\begin{array}{c}3.91 \\
(0.65)\end{array}$ \\
\hline
\end{tabular}

Standard deviations in parentheses.

*In this and subsequent tables $\mathrm{A}$ and $\mathrm{B}=$ Tuesday morning and afternoon values, respectively; $\mathrm{C}$ and $\mathrm{D}=\mathrm{Friday}$ morning and afternoon values, respectively.

TABLE 2

CHANGES IN F.E.V.1.0 FOR THE ENTIRF SERIES

\begin{tabular}{|c|c|c|c|c|c|c|}
\hline No. & Decrease in F.E.V.1.0 & $\bar{x}$ & n & $\mathbf{s}$ & $\mathbf{t}$ & $\mathbf{P}$ \\
\hline $\begin{array}{l}1 \\
2 \\
3 \\
4\end{array}$ & $\begin{array}{l}\mathbf{A} \rightarrow \mathbf{B} \\
\mathbf{C} \rightarrow \mathbf{D} \\
\mathbf{A} \rightarrow \mathbf{D} \\
\mathbf{A} \rightarrow \mathbf{C}\end{array}$ & $\begin{array}{l}-0.085 \\
-0.058 \\
-0.057 \\
+0.002\end{array}$ & $\begin{array}{l}46 \\
40 \\
40 \\
40\end{array}$ & $\begin{array}{l}0.232 \\
0.238 \\
0.263\end{array}$ & $\begin{array}{l}2.46 \\
1.33 \\
0.43\end{array}$ & $\begin{array}{c}<0.02>0.01 \\
<0.20>0.10 \\
<0.70>0.60 \\
\text { n.s. }\end{array}$ \\
\hline
\end{tabular}


(Tuesday morning to Friday afternoon) (Table 2.3). The mean values on Tuesday and Friday mornings were virtually identical (Table 2.4). It is of interest that if the changes over both Tuesday and Friday shifts are averaged for each man, a significant decrease of $74 \mathrm{ml}$. is found. Except where otherwise stated, consideration of the influence of various factors on the changes in F.E.V.1.0 Tuesday's observations.

Influence of Dust Exposure.-Eight of the 46 men were considered to have had minimal exposure to dust on Tuesday; they showed a negligible and statistically insignificant decrease in F.E.V. $\cdot_{\cdot \mathbf{1 \cdot 0}}$ of $36 \mathrm{ml}$. (Table 3.1). The remaining 38 workers who were moderately or severely exposed to dust showed a significant decrease of $95 \mathrm{ml}$. (Table 3.2). Of these 38 , the 13 men who had the most severe exposure suffered a significant mean decrease of $130 \mathrm{ml}$. (Table 3.3). However, the difference between the means for those with minimal and those with maximal exposure is not statistically significant (Table 3.4). Average decreases of the order of 55 to $90 \mathrm{ml}$. were found in those moderately and/or severely exposed to dust during Friday (Table 3.6, 3.7) and over the entire week (Table 3.9, 3.10), but these decreases are not statistically significant and were found not to differ significantly from the mean decreases of $60 \mathrm{ml}$. and $17 \mathrm{ml}$. observed in those with minimal exposure (Table $3.5,3.8$ ).

The decreases noted are not related to the prevalence of smoking, for half of each group (those with minimal, moderate, and severe dust exposure) were smokers. One of the eight men with minimal exposure, three of the 13 with severe exposure, and nine of the 25 with moderate exposure were observed to have a productive cough. The significance of this sign is further examined below, but at this point it must be noted that, if those with productive cough are excluded, the mean F.E.V.1.0 moderately and those severely exposed are the same (about $65 \mathrm{ml}$.). Neither fall is significant (Table 3.11, 3.12 ) in itself nor in comparison with the mean decrease found in those with minimal exposure (36 ml.).

It is concluded that an effect of dust exposure, irrespective of severity, on the ventilatory capacity of the men without productive cough is unproven. The significant fall in F.E.V.1.0 observed in the entire series on Tuesday, and the inconclusive findings on Friday, thus demand further study in terms of the possible relevance of a productive cough.

Influence of a Productive Cough.-Thirteen men were observed to have a productive cough on request, either on Tuesday or Friday morning. The mean decrease in F.E.V $\cdot \cdot_{1 \cdot 0}$ on Tuesday for those with a productive cough was highly significant $(190 \mathrm{ml}$.) (Table 4.1) and for the remainder insignificant (43 ml.) (Table 4.2); the difference between these two means just fails to reach the $5 \%$ significance level (Table 4.3). On Friday the mean decrease for those with a productive cough (reduced to 11 men because of defaulters) is not significant (55 ml.) (Table 4.4) but, in marked contrast to the negligible decrease for those without productive cough $(7 \mathrm{ml}$.) (Table 4.6), this group shows a significant fall in F.E.V..$_{1 \cdot 0}$ of $187 \mathrm{ml}$. over the whole week (Tuesday a.m. to Friday

TABLE 3

CHANGES IN F.E.V.1.0 IN RELATION TO DUST EXPOSURE

\begin{tabular}{|c|c|c|c|c|c|c|}
\hline No. & Decrease in F.E.V.1.0 & $\bar{x}$ & $\mathrm{n}$ & $\mathbf{s}$ & $t$ & $\mathbf{P}$ \\
\hline 1 & $A \rightarrow B$ & -0.036 & 8 & & & n.s. \\
\hline 2 & $\underset{A \rightarrow B}{\text { Minimal dust exposure }}$ & -0.095 & 38 & $0 \cdot 229$ & $2 \cdot 56$ & $<0.02>0.01$ \\
\hline 3 & Moderate and severe dust exposure & $-0 \cdot 130$ & 13 & $0 \cdot 229$ & $2 \cdot 05$ & $<0.05>0.02$ \\
\hline 4 & $\begin{array}{l}\text { Severe dust exposure } \\
\text { Comparison of } 1 \text { and } 3\end{array}$ & & 21 & $0 \cdot 238$ & 0.880 & $<0.40>0.30$ \\
\hline 5 & $\underset{\text { Minimal dust exposure }}{C}$ & -0.060 & 8 & & & n.s. \\
\hline 6 & $\underset{C}{C} \rightarrow$ D & -0.057 & 32 & $0 \cdot 260$ & $1 \cdot 25$ & $<0.30>0.20$ \\
\hline 7 & $\begin{array}{l}\text { Moderate and severe dust exposure } \\
\mathbf{C} \rightarrow \mathbf{D} \\
\text { Severe dust exposure }\end{array}$ & -0.065 & 10 & $0 \cdot 261$ & $0 \cdot 787$ & $<0.50>0.40$ \\
\hline 8 & $\underset{\text { Minimal dust exposure }}{A} \rightarrow \mathbf{D}$ & -0.017 & 8 & & & n.s. \\
\hline 9 & $\begin{array}{l}\mathrm{A} \rightarrow \mathrm{D} \\
\text { Moderate and severe dust exposure }\end{array}$ & -0.066 & 32 & $0 \cdot 270$ & $1 \cdot 38$ & $<0.20>0.10$ \\
\hline 10 & $\begin{array}{l}\mathrm{A} \rightarrow \mathbf{D} \\
\text { Severe dust exposure }\end{array}$ & -0.091 & 10 & 0.379 & 0.72 & $<0.50>0.40$ \\
\hline 11 & $\overrightarrow{\text { Moderate and severe dust exposure; unproductive }}$ & -0.063 & 26 & 0.229 & 1.40 & $<0 \cdot 20>0 \cdot 10$ \\
\hline 12 & $\begin{array}{l}\stackrel{\operatorname{cougn}}{A} \rightarrow \mathbf{B} \\
\text { Severe dust exposure; unproductive cough }\end{array}$ & -0.066 & 10 & $0 \cdot 208$ & $1 \cdot 60$ & $<0.40>0.30$ \\
\hline
\end{tabular}


TABLE 4

CHANGES IN F.E.V.,.o IN RELATION TO OBSERVED COUGH

\begin{tabular}{|c|c|c|c|c|c|c|}
\hline No. & Decrease in F.E.V.1.0 & $\bar{x}$ & $\mathbf{n}$ & $\mathbf{s}$ & $\mathbf{t}$ & $\mathbf{P}$ \\
\hline 1 & $\begin{array}{l}\text { A } \rightarrow \text { B } \\
\text { Productive cough }\end{array}$ & $-0 \cdot 190$ & 13 & 0.231 & $2 \cdot 97$ & $<0.02>0.01$ \\
\hline 2 & $\begin{array}{l}\mathbf{A} \rightarrow \mathbf{B} \\
\text { Unproductive cough }\end{array}$ & -0.043 & 33 & $0 \cdot 222$ & $1 \cdot 11$ & $<0.30>0.20$ \\
\hline 3 & Comparison of 1 and 2 & & 46 & $0 \cdot 224$ & $2 \cdot 01$ & $<0.10>0.05$ \\
\hline 4 & $\begin{array}{l}\mathrm{C} \rightarrow \mathrm{D} \\
\text { Productive cough }\end{array}$ & -0.055 & 11 & $0 \cdot 156$ & $1 \cdot 17$ & $<0.30>0.20$ \\
\hline 5 & $\begin{array}{l}\mathrm{A} \rightarrow \mathrm{D} \\
\text { Productive cough }\end{array}$ & $-0 \cdot 187$ & 11 & 0.201 & 3.09 & $<0.02>0.01$ \\
\hline 6 & $\begin{array}{l}\text { A } \rightarrow \text { D } \\
\text { Unproductive cough }\end{array}$ & -0.007 & 29 & & & n.s. \\
\hline 7 & Comparison of 5 and 6 & & 40 & $0 \cdot 264$ & 1.93 & $<0.10>0.05$ \\
\hline 8 & $\begin{array}{l}\mathrm{A} \rightarrow \mathrm{C} \\
\text { Productive cough }\end{array}$ & $-0 \cdot 124$ & 11 & $0 \cdot 164$ & $2 \cdot 51$ & $<0.05>0.02$ \\
\hline 9 & $\begin{array}{l}\mathrm{A} \rightarrow \mathrm{C} \\
\text { Unproductive cough }\end{array}$ & +0.049 & 29 & & & n.s. \\
\hline 10 & Comparison of 8 and 9 & & 40 & $0 \cdot 218$ & $2 \cdot 24$ & $<0.05>0.02$ \\
\hline
\end{tabular}

p.m.) (Table 4.5). Again, a comparison of the means for those with and without a productive cough approaches the $5 \%$ level (Table 4.7). An important related finding is a significant change in ventilatory capacity between Tuesday and Friday mornings; those with a productive cough, showing a significant mean fall of $124 \mathrm{ml}$., differ significantly from those without a productive cough, who show a small but insignificant rise (49 ml.) (Table 4.8, 4.9, 4.10).
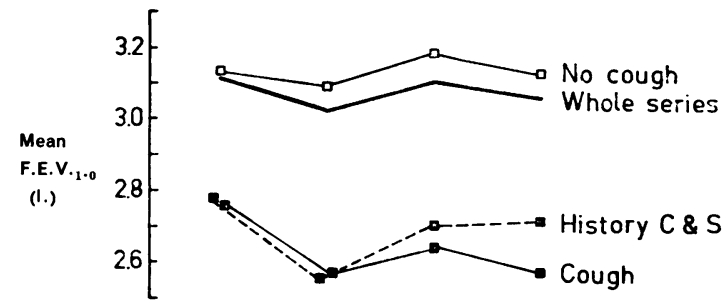

A B C D

FIG. 1.- Change in mean F.E.V.1.0 over a working week for the entire series, for those with and without an observed productive cough, and for those giving a history of persistent cough and syutum (C and S).

A and B: Tuesday morning and afternoon values, respectively.

$\mathrm{C}$ and $\mathrm{D}$ : Friday morning and afternoon values, respectively.

It must be pointed out that whereas all but one of the men with a productive cough were classified as exposed to some dust, seven of the 33 without such a cough were regarded as exposed to negligible dust. However, exclusion of these seven men makes no pertinent difference to the analysis. The conclusion remains that a significant fall in F.E.V. $\cdot_{\cdot \mathbf{1 \cdot 0}}$ is found on Tuesday in those with a productive cough but not in the remainder. Again by comparison with the remainder, this decrease tends to be maintained throughout the week, no significant further decrease being observed during Friday's exposure. The pattern is illustrated graphically in Figure 1.
Influence of Smoking.-Examination of the data in terms of smoking habit shows results somewhat similar to those relating to productive cough. Indeed, a relationship between smoking and a productive cough is suggested by the fact that 10 of the 13 men with productive cough, and only 14 of the 33 without it, were smokers. On Tuesday, a significant mean decrease in F.E.V.1.0 $138 \mathrm{ml}$. (Table 5.1) is found in the 24 smokers, compared with $13 \mathrm{ml}$. for 22 non-smokers (Table 5.2); the difference between these means approaches statistical significance (Table 5.3). On Friday the mean decrease in F.E.V $\cdot_{\cdot 1 \cdot 0}$ is greater in the non-smokers (Table 5.4, 5.5), a finding related to the tendency for an increase in F.E.V.1.0 in non-smokers between Tuesday and Friday mornings and towards a decrease in the smokers (Table 5.6, 5.7). None of these changes or differences is statistically significant (Table 5.8), and both smokers and non-smokers show insignificant falls in F.E.V.1.0 ${ }_{\cdot 1 \cdot 0}$ over the entire week (Table 5.9, 5.10). The pattern is illustrated in Fig. 2 and its resemblance to Fig. 1 is seen.

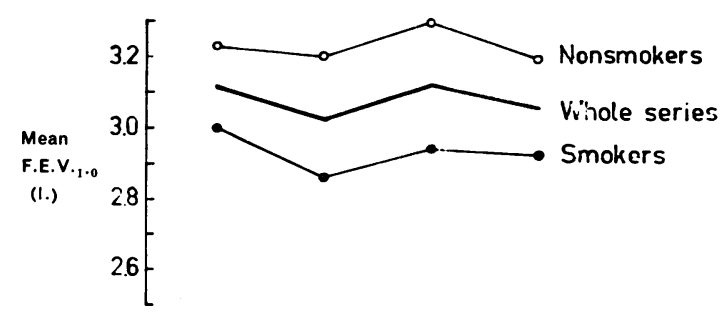

A $B \quad$ C $\quad$ D

FrG. 2. Change in mean F.E.V.1.0 over a working week for smokers and non-smokers and for the series as a whole.

$A$ and B: Tuesday morning and afternoon values, respectively.

$\mathrm{C}$ and D: Friday morning and afternoon values, respectively. 
TABLE 5

CHANGES IN F.E.V.1.0 IN RELATION TO SMOKING

\begin{tabular}{|c|c|c|c|c|c|c|}
\hline No. & Decrease in F.E.V.1.0 & $\overline{\mathbf{x}}$ & $\mathbf{n}$ & s & $t$ & $\mathbf{P}$ \\
\hline 1 & $\mathbf{A} \rightarrow \mathbf{B}$ & -0.138 & 24 & $0 \cdot 257$ & $2 \cdot 63$ & $<0.02>0.01$ \\
\hline 2 & $\begin{array}{l}\text { Smokers } \\
\mathbf{A} \rightarrow \text { B }\end{array}$ & -0.013 & 22 & & & n.s. \\
\hline 3 & Comparison of 1 and 2 & & 46 & $0 \cdot 227$ & 1.69 & $<0.10>0.05$ \\
\hline 4 & $\mathrm{C} \rightarrow \mathrm{D}$ & -0.021 & 21 & & & n.s. \\
\hline 5 & C $\rightarrow$ D & -0.099 & 19 & $0 \cdot 280$ & 1.54 & $<0.20>0.10$ \\
\hline 6 & A $\rightarrow$ C & -0.050 & 21 & $0 \cdot 242$ & 0.95 & $<0.40>0.30$ \\
\hline 7 & A $\rightarrow$ C & +0.058 & 19 & $0 \cdot 207$ & $1 \cdot 22$ & $<0.30>0.20$ \\
\hline 8 & Comparison of 6 and 7 & & 40 & $0 \cdot 225$ & 1.51 & $<0.20>0.10$ \\
\hline 9 & $\underset{\text { Smokers }}{\mathbf{A} \rightarrow \mathbf{D}}$ & -0.070 & 21 & $0 \cdot 258$ & $1 \cdot 24$ & $<0.30>0.20$ \\
\hline 10 & $\begin{array}{l}\mathrm{A} \rightarrow \mathrm{D} \\
\text { Non-smokers }\end{array}$ & -0.041 & 19 & & & n.s. \\
\hline
\end{tabular}

Interrelationship of Dust Exposure, Smoking Habit, and Productive Cough.-It is of interest to examine separately the ventilatory capacity in smokers and non-smokers with and without productive cough, limiting the analyses to those with moderate or severe dust exposure. It is found that the nine smokers with a productive cough and dust exposure show a significant mean decrease in F.E.V. ${ }_{1 \cdot 0}$ of $186 \mathrm{ml}$. (Table 6.1) on Tuesday, whereas the 11 smokers without productive cough exposed to dust show a mean (insignificant) fall of $131 \mathrm{ml}$. (Table 6.2). These figures may be compared with those for the three non-smokers with a productive cough and dust exposure (mean decrease, $103 \mathrm{ml}$.) and the 15 exposed non-smokers without a productive cough (mean decrease, $12 \mathrm{ml}$.) (Table 6.3); a comparison of the latter with the decrease noted for smokers with cough just fails to reach significance (Table 6.4).
As previously noted (Table 3.1 ), the remaining eight men with negligible dust exposure (including one with a productive cough) showed an insignificant mean decrease of $36 \mathrm{ml}$. on the same day (Tuesday).

On Friday, and over the entire week, a similar pattern of reaction is found in the several groups, although with the small numbers none of the differences between groups reaches statistical significance. However, between Tuesday and Friday mornings, the exposed smokers with cough show a decrease in F.E.V $\cdot_{\cdot 1 \cdot 0}$ of $93 \mathrm{ml}$. (Table 6.5) whereas the non-smokers without cough show an increase of $100 \mathrm{ml}$. (Table 6.7); although neither is significant in itself, the difference between the two is significant (Table 6.8). The smokers without cough show an intermediate fall (Table 6.6, 6.9). It seems likely that in those who smoke and cough the reduction in ventilatory capacity occurring during the first day

TABLE 6

CHANGES IN F.E.V. $\cdot \cdot \cdot$ IN RELATION TO OBSERVED COUGH, SMOKING, AND DUST EXPOSURE

\begin{tabular}{|c|c|c|c|c|c|c|}
\hline No. & Decrease in F.E.V.1.0 & $\overline{\mathbf{x}}$ & $\mathbf{n}$ & $\mathbf{s}$ & $\mathbf{t}$ & $\mathbf{P}$ \\
\hline 1 & $\mathrm{~A} \rightarrow \mathbf{B}$ & $-0 \cdot 186$ & 9 & $0 \cdot 242$ & $2 \cdot 31$ & 0.05 \\
\hline 2 & $\begin{array}{l}\mathrm{A} \rightarrow \mathrm{B} \\
\text { Smokers with unproductive cough and with dust } \\
\text { exposure }\end{array}$ & $-0 \cdot 131$ & 11 & $0 \cdot 250$ & $1 \cdot 74$ & $<0.20>0.10$ \\
\hline 3 & $\begin{array}{l}A \rightarrow B \\
\text { Non-smokers without cough and with dust } \\
\text { exposure }\end{array}$ & -0.012 & 15 & & & n.s. \\
\hline 4 & Comparison of 1 and 3 & & 24 & $0 \cdot 220$ & 1.89 & $<0.10>0.05$ \\
\hline 5 & $\underset{\text { Smokers with cough and dust exposure }}{\mathrm{A} \rightarrow \mathrm{C}}$ & -0.093 & 7 & $0 \cdot 123$ & 1.85 & $<0.20>0.10$ \\
\hline 6 & $\begin{array}{l}\stackrel{A}{A} \rightarrow \text { C } \\
\text { Smokers without cough and with dust exposure }\end{array}$ & -0.066 & 10 & $0 \cdot 202$ & 1.03 & $<0.40>0.30$ \\
\hline 7 & $\begin{array}{l}\mathrm{A} \rightarrow \mathrm{C} \\
\text { Non-smokers without cough and with dust } \\
\text { exposure }\end{array}$ & $+0 \cdot 100$ & 12 & 0.214 & 1.62 & $<0.20>0.10$ \\
\hline 8 & Comparison of 5 and 7 & & 19 & $0 \cdot 187$ & $2 \cdot 17$ & $<0.05>0.02$ \\
\hline 9 & Ccmparison of 6 and 7 & & 22 & $0 \cdot 209$ & 1.61 & $<0.20>0.10$ \\
\hline
\end{tabular}


back at work does not readily disappear overnight but tends to be maintained throughout the working week, presumably with recovery over the weekend.

Influence of Previously Impaired Ventilatory Capacity.-Many investigations now testify to the adverse effect of smoking on ventilatory capacity, and a productive cough under observation has been found to be associated with an average reduction in F.E.V $\cdot_{\cdot 1 \cdot 0}$ of approximately 0.5 litre in a male working population (Gandevia and Ritchie, in preparation). In these circumstances it is pertinent to examine the relationship between the observed decreases in F.E.V.1.0 in the present study and ventilatory capacity measurements made on Tuesday morning after three days away from dust.

No correlation was apparent when the initial level of F.E.V.1.0, either as an absolute value or as a percentage of predicted normal, was plotted against the decreases in F.E.V.$_{1 \cdot 0}$ observed on Tuesday; in fact the correlation coefficients were of the order of $0 \cdot 1$. However, Figs. 1 and 2 show the lower mean F.E.V.1.0 for those with productive cough $(2 \cdot 76 \pm$ 0.46 litres) and for those who smoke (3.00 \pm 0.67 litres) compared with $3.24 \pm 0.62$ litres and $3.23 \pm 0.54$ litres for those without productive cough and for non-smokers; the difference in the former group is significant $(\mathrm{P}<0.02>0.01)$. It is within the former groups that the greater and more significant decreases in F.E.V.1.0 have been demonstrated on initial exposure, so that to this extent at least there is probably some significance to previous impairment of ventilatory capacity.

The correlation coefficient for the forced expiratory ratio (F.E.V.1.0 $/$ F.V.C.) and the observed decreases is also not significant $(r=0 \cdot 1335, n=46)$. However, the mean decrease in F.E.V $\cdot_{\cdot 1 \cdot 0}$ on Tuesday for the 15 subjects with an initial forced respiratory ratio of 0.70 to 0.79 is $144 \mathrm{ml}$. $(\mathrm{P}<0.05>0.02)$, whereas there is only an insignificant average decrease of $37 \mathrm{ml}$. in the 21 subjects with a forced expiratory ratio of 0.80 to 0.89 . The decrease for the four subjects with an initial ratio less than 0.70 is $180 \mathrm{ml}$., while for the six subjects with a ratio of 0.90 or above a small average decrease of $42 \mathrm{ml}$. is found. The trend towards greater decreases in those with lower ratios is thus suggestive. The reason for this trend may be found in the average forced expiratory ratio recorded in those with productive cough $(0 \cdot 767)$, significantly lower than the average of 0.820 for the remainder $(P<0.05>0.02)$, and, to a lesser extent, in the smokers $(0.787)$ compared with the non-smokers $(0.827)(\mathrm{P}<0.10>0.05)$. It may be mentioned that the F.V.C., as well as F.E.V.1.0, tended to decrease during the day in those who smoke and those who have productive cough, so that the ratio is not as sensitive an index of change in ventilatory capacity as the F.E.V.1.0

Influence of Duration of Employment.-Six men, all non-smokers, had been employed for less than a month. They showed a significant mean decrease in F.E.V. ${ }_{1 \cdot 0}$ of $140 \mathrm{ml}$. on Tuesday (Table 7.1), and it is of interest that three of them were absent or had resigned by Friday. Twelve men, including five smokers, had been employed for over a month but not more than a year; their F.E.V .1.0 $_{\text {.0 }}$ over Tuesday showed a small mean increase of $43 \mathrm{ml}$. (Table 7.2). The difference between these means approaches significance (Table 7.3), and it may be recalled that the mean decrease for the whole series on this day was $85 \mathrm{ml}$. The findings are not conclusive but they raise the question of either the development of tolerance or the possibility of early selection, whereby an 'affected' worker soon excludes himself from the job.

Influence of a History of Cough and Sputum.Analysis of the data in terms of a history of cough and sputum is possible only for the 25 Englishspeaking subjects for whom the questionnaire was completed. Eleven of these men admitted to cough and sputum for more than three months of the year; they showed a significant mean decrease in F.E.V.1.0 on Tuesday of $124 \mathrm{ml}$. (Table 8.1). A comparison of this decrease with that for the 14 men with no such history $(51 \mathrm{ml}$.) does not reveal a significant difference (Table 8.2, 8.3).

These findings may be considered in relation to those for the observed sign of productive cough within the same group of men. Eleven of the group had a productive cough, comprising five men who admitted to sputum and six who did not; they showed a significant mean decrease in F.E.V.1.0 $175 \mathrm{ml}$. (Table 8.4), thus differing significantly from

TABLE 7

CHANGES IN F.E.V.1.0 IN RELATION TO DURATION OF EMPLOYMENT

\begin{tabular}{|c|c|c|c|c|c|c|}
\hline No. & Decrease in F.E.V.1.0 & $\bar{x}$ & $\mathbf{n}$ & $\mathbf{s}$ & $\mathbf{t}$ & $\mathbf{P}$ \\
\hline 1 & $\mathbf{A} \rightarrow \mathbf{B}$ & $-0 \cdot 140$ & 6 & $0 \cdot 125$ & $2 \cdot 74$ & $<0.05>0.025$ \\
\hline 2 & $\begin{array}{l}\text { Employed one month or less } \\
\text { A } \rightarrow \text { B } \\
\text { Employed one year or less }\end{array}$ & +0.043 & 12 & $0 \cdot 193$ & $0 \cdot 77$ & $<0.50>0.40$ \\
\hline 3 & Comparison of 1 and 2 & $0 \cdot 183$ & 18 & $0 \cdot 174$ & $2 \cdot 10$ & $<0.10>0.05$ \\
\hline
\end{tabular}


TABLE 8

CHANGES IN F.E.V.1.॰ IN RELATION TO HISTORY OF COUGH AND SPUTUM AND TO OBSERVED COUGH

\begin{tabular}{|c|c|c|c|c|c|c|}
\hline No. & Observation & $\bar{x}$ & $\mathbf{n}$ & $\mathbf{s}$ & $t$ & $\mathbf{P}$ \\
\hline $\begin{array}{l}1 \\
2 \\
3 \\
4 \\
5 \\
6\end{array}$ & $\begin{array}{l}\text { Positive } A \rightarrow B \\
\text { Negative } A \rightarrow B \\
\text { Comparison of } 1 \text { and } 2 \\
\text { Productive cough } A \rightarrow B \\
\text { Unproductive cough } \vec{A} \rightarrow \text { B } \\
\text { Comparison of } 4 \text { and } 5\end{array}$ & $\begin{array}{l}-0.125 \\
-0.051 \\
-0.074 \\
-0.175 \\
-0.012 \\
-0.163\end{array}$ & $\begin{array}{l}11 \\
14 \\
25 \\
11 \\
14 \\
25\end{array}$ & $\begin{array}{l}0.262 \\
0.236 \\
0.248 \\
0.236 \\
0.236 \\
0.236\end{array}$ & $\begin{array}{l}1.58 \\
0.74 \\
2.46 \\
1.71\end{array}$ & $\begin{array}{l}<0.20>0.10 \\
\text { n.s. } \\
<0.50>0.40 \\
<0.05>0.025 \\
\text { n.s. } \\
0.10\end{array}$ \\
\hline
\end{tabular}

those without a productive cough (mean decrease, $12 \mathrm{ml}$.) (Table 8.5, 8.6).

The response for the rest of the week in those with a history of cough is illustrated in Fig. 1; there is still a small but statistically insignificant decrease on Friday morning compared with Tuesday morning, and no further change occurs during Friday. The response of the group thus resembles that for the men with the sign of productive cough, also shown in Fig. 1, but the changes are less impressive.

\section{Discussion}

Our results indicate a significant decrease in F.E.V .1.0 $_{10}$ in workers exposed predominantly to jute dust during the first day at work after a long weekend, but no significant further decrease occurred in the group as a whole on the final working day of the week or over the entire week. Closer analysis reveals that this decrease was virtually confined to those who were observed to have a productive cough on request and to those who smoked, almost all of the former group being smokers. In these groups there was a strong tendency for the observed decrease on Tuesday to persist throughout the week. Those who smoked, and more particularly those who had a productive cough, had lower ventilatory capacities and lower forced expiratory ratios than the remainder; to this extent those with the greater impairment of ventilatory capacity showed the more significant decreases.

In relating the observed changes in ventilatory capacity to dust exposure, we concede that the internal design of the present study did not-and could not-allow for observation of the 'positive reactors' during a working shift without exposure to dust. Nonetheless, the evidence in the relevant paragraphs above is consistent with, if not suggestive of, the view that some exposure to dust was necessary to produce the observed falls in F.E.V.1.0. In particular, the mere fact that a significant decrease was demonstrated on Tuesday is important, for it is now generally accepted that no significant decrease will occur in an average working population unless there is some specific environmental hazard. By contrast, in those with established obstructive lung disease, ventilatory capacity tends to rise during the day (Lewinsohn, Capel, and Smart, 1960). Furthermore, if a decrease in ventilatory capacity were the usual behaviour of smokers and those with sputum, it is difficult to see why there should not have been a similar significant fall on Friday, and why there should be a definite tendency for a decrease between Tuesday and Friday mornings, with the implication that there is a rise over the weekend. There remains the possibility that the observed productive cough is a reflection of dust exposure in susceptible subjects, who are in fact those who show the greater reduction in ventilatory capacity on exposure. From data obtained in surveys of other populations with and without an occupational hazard (Mackay, O'Sullivan, Ritchie, and Gandevia, unpublished data) we can confidently state that, at least in the southern states of this country, a productive cough, as defined, is essentially a function of smoking and not of occupation. It has already been pointed out that the figures from the present study are consistent with this view.

Two other studies of ventilatory capacity in jute workers during exposure have been reported. Mair, Smith, Wilson, and Lockhart (1960) found no significant changes in ventilatory capacity in eight jute workers during Monday or Thursday, nor, to judge from their Fig. 1, between Monday and Thursday mornings. The smoking habits and sputum status of the subjects are not recorded. Gilson, Stott, Hopwood, Roach, McKerrow, and Schilling (1962) also found no significant change in 20 men during an unusually dusty Monday shift. Five of these men, working in some of the dustier areas, had symptoms of bronchitis, but they also showed no significant or consistent change in ventilatory capacity. Our findings are not necessarily in serious conflict with these results; in a larger series, we have essentially shown a small decrease in ventilatory capacity chiefly affecting a defined section of the total work force. It is, of course, possible that there are differences in the severity of dust exposure, in the distribution of particle size or in the biological activity of the dust. Furthermore, after our comparable survey of cotton workers (Gandevia and Milne, 1965), we agree with others who have studied both industries that cotton 
dust is the more potent and consistent in its effect on ventilatory capacity during a shift (Gilson et al., 1962), a conclusion in accord with bio-assays of smooth muscle constrictor substance in both groups (Nicholls, 1962).* None of the jute workers interviewed in detail gave a history suggestive of byssinosis.

The fact that a cough under observation on request can be used to define a group within a small occupational population which shows a pattern of ventilatory response to an inhaled irritant different from that of the rest of the population is of particular interest. We have previously noted this in a series of men exposed to grain dust and to rock phosphate dust (Gandevia and Ritchie, in preparation) and, less significantly in a small group, in men exposed to isocyanate vapour (Gandevia, 1964). The sign is quickly and easily observed under survey conditions even in reluctant subjects, so that the lapse rate is nil, and it can be used, as in the present study, where there is a language problem. We believe that the sign is of special value in occupational studies, in which we own to some scepticism as to the reliability of the histories of cough and sputum, especially in industries where there is a known or suspected hazard.

The finding of more consistent and significant decreases in F.E.V.1.0 in the men with an observed productive cough, as compared with those merely giving a history of cough, supports this view. Similar observations were also made in the abovementioned study of the effects of exposure to grain dust and again, although there was the expected overlap between those with a history and those with the sign of productive cough, there was reason to believe that the sign was defining a slightly different population rather than merely the more severely affected members of the population with a positive history. Clearly, further work is required to establish the full significance of the sign, and some additional studies are currently in progress. Provisionally, on the basis of this survey and others, we believe that it defines better than the history a group with lower ventilatory capacity and a greater tendency to react to inhaled irritants. For epidemiological work, its simplicity and uniform applicability have great appeal. Other evidence, partly impressional and partly based on the study of different factions within the same industry, suggests that economic and political factors may consciously or subconsciously

\footnotetext{
*In the present study, some samples of dust taken from near the garnetting machines were analysed at the Welsh School of Pharmacy, Cardiff. They showed a contractor activity on a smooth muscle preparation of 2.175 units/g., which is less than half that normally occurring in airborne cotton dust.
}

influence replies to questions concerning cough, sputum, and symptoms on exposure, without necessarily any deliberate attempt to mislead. These difficulties are not necessarily obviated by using the morning sputum collection technique so successfully employed by Fletcher, Elmes, Fairbairn, and Wood (1959), and in any case, we have not achieved a sufficient return of sputum jars.

The present investigation also reveals evidence, admittedly inconclusive if the men with productive cough are excluded, that smokers as a group tend to show greater decreases in ventilatory capacity than non-smokers on exposure to jute dust. One of us has published data on the bronchial sensitivity to histamine of smokers and non-smokers exposed to isocyanate at work, and concluded that, although the bronchi might show some tolerance to one irritant, they were likely to react adversely to two (Gandevia, 1963). Our results in the jute workers may perhaps be viewed as a further illustration of a general principle, a principle which may be extended to include the possible interaction between air pollution and smoking in the development of chronic bronchitis. It also follows from this reasoning that it may be easier in an environment relatively free of air pollution to isolate the effects of occupational irritants, and to illustrate the relevance of such factors as smoking and productive cough to the ventilatory response observed.

We are indebted to Miss Heather Steel, B.Sc., for the statistical analysis and for preparing the figures, and to Mrs. Wendy Britten for patient secretarial assistance. We are very grateful to Dr. P. J. Nicholls and Mrs. J. Thomas, of the Welsh School of Pharmacy, who assayed the dust samples. Our thanks are due to Dr. F. Croll and the management and employees of the firm concerned for their whole-hearted co-operation. We also gratefully acknowledge the collaboration of Dr. K. Brennan, Chief Health Officer, and Dr. A. Christophers, of the Industrial Hygiene Division, Health Department of Victoria, whereby one of us was granted study leave to carry out this work.

\section{REFERENCES}

Fletcher, C. M., Elmes, P. C., Fairbairn, A. S., and Wood, C. H (1959). Brit. med. J., 2, 257.

Gandevia, B. (1963). Brit. J. industr. Med., 20, 204.

- (1964). Aust. Ann. Med., 13, 157.

- and Milne, J. (1965). In preparation.

Gilson, J. C., Stott, H., Hopwood, B. E. C., Roach, S. A., McKerrow, C. B., and Schilling, R. S. F. (1962). Brit. J. industr. Med., 19, 9 .'

Lewinsohn, H. C., Capel, L. H., and Smart, J. C. (1960). Brit. med. J., $1,462$.

Mair, A., 1, S62. Brit. J. industr. Med., 17, 272.

Medical Research Council (1960). Brit. med. J., 2, 1665.

Nicholls, P. J. (1962). Ibid., 19, 33. 